\title{
Selection of Switching Frequency for H. F. Mirror Inverter Employed in Industrial Induction Heating
}

\author{
Nitai Pal, Pradip Kumar Sadhu, and Atanu Bandyopadhyay
}

\begin{abstract}
An exhaustive method for verifying \& optimizing of switching frequency for the performance of high frequency mirror inverter for induction heater is presented. Litz-wire is used for heating coil of the induction heater which controls the skin effect and proximity effect of conductor operating at high frequency. With the calculated optimum values of inductance and resistance at a particular operating frequency, HF mirror inverter topology has been simulated using P-SIM. Optimum results are obtained by changing the switching frequency. Obtained results are then compared using different power semi-conductor switches like IGBT, BJT, MOSFET and GTO. Afterwards waveforms have been shown \& we can see that at a particular switching frequency output is highly quality \& can justify the feasibility for real implementation of high frequency mirror inverter fed induction heater in industrial appliances
\end{abstract}

Index Terms-Induction heating, mirror inverter, P-SIM, semi-conductor switches, ZCS and ZVS

\section{INTRODUCTION}

Induction heater for industrial applications operates at a high frequency range from $1 \mathrm{kHz}$ to $100 \mathrm{kHz}$ [1]. Here switching frequency varies between $20 \mathrm{kHz}$ to $40 \mathrm{kHz}$. In the application of low frequency induction heating, the temperature distribution can be controlled by slowly varying magnetic fields below a frequency as low as 300 Hz. For medium frequency application, an auxiliary voltage-fed inverter is operated in parallel with the main current-fed inverter since the current-fed parallel inverters alone, when used for induction heating, fail to start. Mirror inverters [2], [3] for high frequency induction heating and melting applications are self-started. For self-commutation, a resonant circuit is essential. It is assumed that the circuit is under damped; a mandatory condition for the circuit. The capacitor required for under damping can be connected in series or in parallel with the load. In the modern times, IGBTs, MOSFETs, GTOs are preferred to SCRs mainly because they offer convenient turn OFF

Manuscript submitted on July 15, 2011; revised February 19. 2012. This work was partially supported by the Unversity Grant Commission, India

N. Pal and P. K. Sadhu are with Electrical Engineering Department, Indian School of Mines, Dhanbad, Jharkhand 826004, India (e-mail: nitai_pal@rediffmail.com,_ pradip_sadhu@yahoo.co.in; Tel.: +91326-2235478; fax: +91326-2296563).

A. Bandyopadhyay is with Electrical Engineering Department, Asansol Engineering College, Asansol, and West Bengal, India. (e-mail: banerjee_atanu77123@rediffmail.com) characteristics. Some auxiliary circuits and equipment are required to minimize switching losses occurring at high frequencies. The requirements for the induction heaters are as follows [4]:

- Switching in high-frequency range

- High efficiency

- Power factor close to unity

- Wide power range and

- Reliability.

Induction heaters are usually designed to operate with a heating plate or pipeline made from a specific material [5], mainly cast iron or Ferro-magnetic stainless steel. The following is therefore desired characteristic for the inverter;

- No reactive components other than the heating coil and the non-smooth filter inductor,

- No input or matching transformers,

- $50 \%$ duty ratio, simplifying the control and gate circuits,

- Zero current switching (ZCS) and / or zero voltage switching (ZVS) [6],

- Clamped switch voltage and / or current,

- The use of uncontrolled voltage source.

Different inverter topologies suitable for induction heating and melting applications are presented in. The comparison is based on the criteria such as input power factor, component ratings, maximum and minimum operating frequencies, operation under varying load conditions, inverter starting capability and system and control simplicity [7]. Llorente et. al., have made a comparison between four inverter topologies commonly used in induction cookers. The considered topologies are the full-bridge inverter, the half-bridge inverter, and two single-switch inverters. All of them are designed for the same specifications and they are compared in aspects such as power device stresses, efficiency, frequency control, and electromagnetic emissions [8]. In these papers, separate inverter configurations have been discussed \& compared, but no light is thrown to the type \& necessity of power semiconductor switches for different inverter topologies [9], [10], [11], [12], [13], [14]. Same circuit can respond differently with the variation in power switches. In this present paper, response of high frequency mirror inverter is tested \& verified in different frequencies and finally appropriateness of the desired frequency is confirmed. With the designed parameters of the said inverter circuit, IGBT is used as switch. Complete inverter configuration has been simulated using P-SIM.

Mirror inverter is powered from single phase AC supply to energize the heating coil which is made of litz wire [15]. This type of wire is configured by many strands of single insulated wire in order to reduce the losses caused by skin effect \& proximity effect. 


\section{ANALYSis OF High FREQUENCY MiRROR INVERTER}

In the circuit operation has been discussed in detail. The exact circuit diagram of the mirror inverter [16] is shown in Fig. 1.

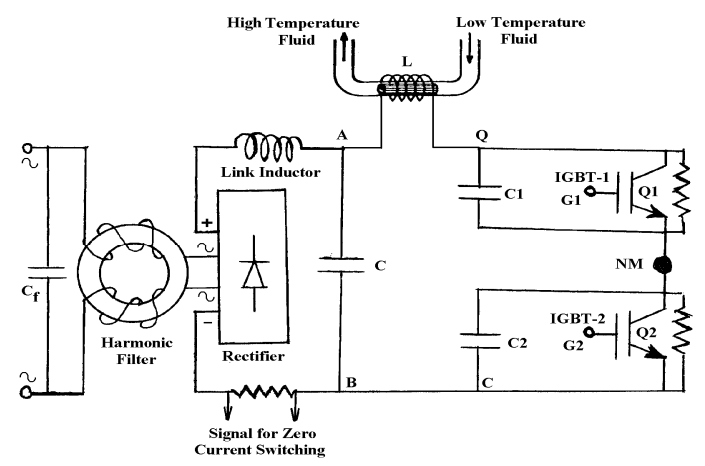

Fig. 1. Circuit diagram of mirror inverter using IGBT.

For operational analysis, equivalent circuit diagram as shown in Figure 2 can be referred. Single point 'NM, in Figure 1 is shown as a stretched bar 'NM' in Figure 2.

When there are no input signals to the IGBTs, both capacitors $\mathrm{C} 1 \& \mathrm{C} 2$ are charged.

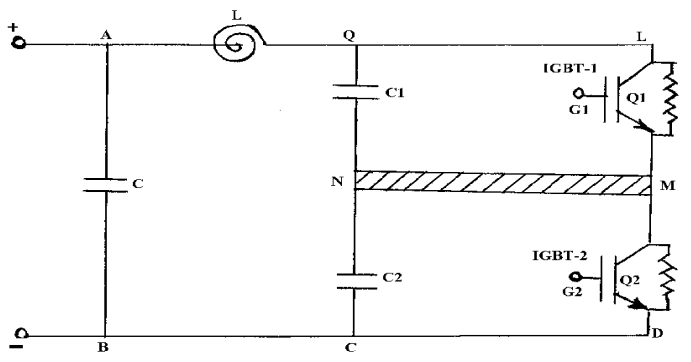

Fig. 2. Circuit diagram of mirror inverter using IGBT.

As soon as gate pulse is applied to IGBT-1, C1 gets discharged through 'QLMN' loop \& C2 gets charged 'QLMNC' path. In the next cycle when input signal is given to IGBT-2 with gate pulse to IGBT-1 is removed, C2 gets discharged through 'NMDC' loop \& C1 gets charged through 'QNMDC' path. Thus a frequency current flows through ' $\mathrm{MN}$ ' bar in alternate direction \& due to the low capacitive reactance of the capacitor ' $\mathrm{C}$ ', this current also flows through the coil inductor. In this way, radio-frequency current generated in the short-circuited bar 'MN' is reflected into the induction coil. Now this current will generate alternating magnetic flux.

A \& B points in the above mentioned circuit .At first when we connect the converter circuit with the D.C power supply of the system the capacitors $\mathrm{C}_{1}$ and $\mathrm{C}_{2}$ are charged when there are no gate pulses at $G_{1}$ and $G_{2}$. While starting high frequency A.C generation, pulses are fed from software control circuit alternatively in the gates of I.G.B.T - 1 and I.G.B.T-2. When the gate pulse is achieved in $\mathrm{G}_{1}$ then I.G.B.T - 1 is in 'ON' state. So the charge of capacitor $C_{1}$ discharges as well as $C_{2}$ charges. By means of this operation current flows in the short circuit bar 'NM' from $\mathrm{M}$ to $\mathrm{N}$.

In the next half of the operation the gate pulse is achieved in $\mathrm{G}_{2}$ of the I.G.B.T- 2 then I.G.B.T- 2 is in ' $\mathrm{ON}$ ' state. Before getting pulse in $\mathrm{G}_{2}$ the gate pulse of $\mathrm{G}_{1}$ is withdrawn to avoid the simultaneous conduction and the short circuit between D.C source terminals. When I.G.B.T -2 is in ' $\mathrm{ON}$ ' state then $\mathrm{C}_{2}$ discharges as well as $\mathrm{C}_{1}$ charges. By means of this operation current flow in the short circuit 'NM' bar from $\mathrm{N}$ to $\mathrm{M}$. So by these gate pulses we generate alternating current in 'NM' bar. This alternating current frequency is in the range of radio-frequency like $33.33 \mathrm{kHz}$.At this high frequency the capacitor C across (A) \& (B) terminals is working as very low impedance path for radio-frequency range [because capacitive impedance, $\left.\quad \mathrm{X}_{\mathrm{C}}=1 /(2 \mathrm{IC})\right]$. So this alternating high frequency current flows through the $(\mathrm{A}),(\mathrm{Q}),(\mathrm{L}),(\mathrm{M}),(\mathrm{N}),(\mathrm{C})$, (B) loop in one half and in next half it will flow through the (A), (Q), (N), (M), (D), (C), (B) loop. .So the generated alternating current through the NM bar will also flow through the induction heating working coil ' $\mathrm{L}$ ' which will generate alternating magnetic flux because it is connected in series.

\section{DESIGN}

A large amount of heat can be produced by the present arrangement. This can be possible by feeding huge amount current to the heating coil at resonance condition. Here we use the current which is known as eddy current loss. If this current can be increase then the amount of heat produce will be increase [17], [18].

\section{A. Structure of the Load Circuit}

A flat heating-coil is used for induction cooking. A thermal insulator is placed in between the heating plate and the heating-coil to protect the coil from overheating and also to support the vessel [19]. A ferrite disc is often used to enhance the coupling but with a small addition in cost. In order to obtain maximum coupling, the spacing between the heating plate and the coil should be kept as small as possible, but at the same time it should be large enough for sufficient support, insulation and airflow. The vessel must be made up of a material for which the product of resistivity and relative permeability is high enough to yield an acceptable efficiency. The heating-coil is usually made up of bundle conductors (Litz wire) and it is forced air-cooled.

\section{B. Design of Circuit Parameters}

The load structure for induction heating may be looked upon as a transformer with the heating plate acting as a short-circuited secondary. Now, on neglecting the magnetizing inductance $(\mathrm{Lm})$ of the $\mathrm{N}$ turn primary, the heating-coil and the heating plate can be represented by an equivalent series combination of inductance [20].

A complete design can be done on the basis of the following assumptions:

- The spacing between the coil and the plate is same throughout.

- The heating-coil has the same inner and outer diameter, independent of the number of turns.

- The cooking vessel remains unchanged.

- The heating-coil is of 37 turns with an outer diameter of $175.5 \mathrm{~mm}$ and an inner diameter of $43.5 \mathrm{~mm}$.

\section{Design of the HF Mirror Inverter}

The following are the important voltage and current parameters for each of the power circuit components : 
Diode Bridge Rectifier: The peak voltage and the average current will specify the requirements for the rectifier module.

Input Capacitor: The main limiting factor for the input capacitor will be the peak voltage. The rms voltage cannot be a limiting factor due to the low grid frequency and the relatively small amplitude of the switching frequency ripples.

Resonant Capacitors: For the resonant capacitor both the peak and the rms voltages are equally important. However, the rms voltage withstand capability of a capacitor decreases significantly at higher frequencies mainly due to increased dielectric and conduction power loss. As a result, dielectric material such as polypropylene is usually used as the best possible substitute.

Heating-coil: The rms current will determine the cross sectional area needed for the conductors for operation at an acceptable current density. Due to the employment of a single layer heating coil, arcing between the turns should not be a problem.

Singular-switches: The peak voltage determines the voltage rating. The current rating, on-state voltage and the turn-off switching time of the IGBT will be determined by its average current, turn-off current.

\section{SAlient Features of the InduCtion Heating EQUIPMENT}

High Power : Since the heating coil does not get hot for the purpose of heating the load, a large heating surface as well as a high temperature heating are both feasible with radio-frequency induction heating.

Flexibility: The distribution of power density in the pipeline or heating plate can be easily changed by changing the coil configuration.

Controllability: The response of load temperature is quite high because of the proposed regulation strategy of the radio-frequency inverter. Implementation of microprocessor-based control can be easily introduced. The regulation of a series resonant variable radiofrequency mirror inverter, operating under a precise temperature setting through the employment of an auto tuning PID-based feedback scheme, would permit stable operation as well as easy control.

High Efficiency: In the proposed scheme, heat is directly generated in the heating plate or pipeline. As a result, there is practically no loss of energy due to transportation. This permits ample amount of energy saving and hence sufficient reduction of running cost. The eddy current in the magnetically conductive metallic package is induced through a contact less radio-frequency power transmission. So, unlike electric heater, there is no scope for any shock hazard.

\section{Testing CONDitions}

The circuit diagram used for the simulation work using P-SIM software is shown in Fig. 3.

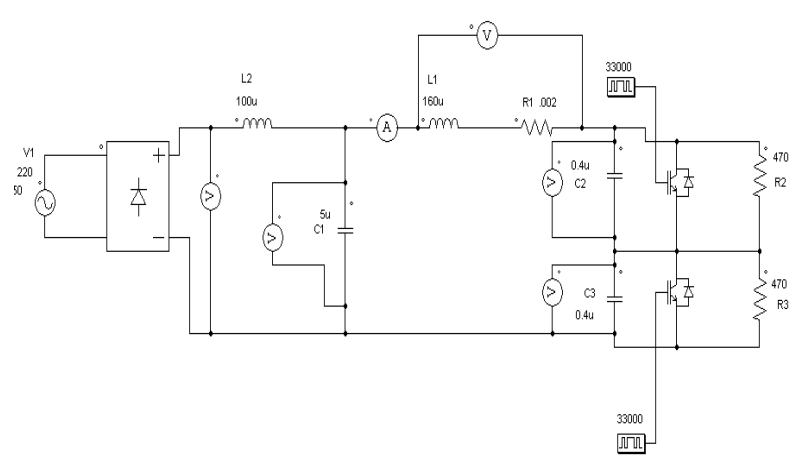

Fig. 3. Circuit diagram for P-SIM simulation of mirror inverter using IGBT.

The chosen parameters for the inverter configuration is given in Table I.

TABLE I: INPUT PARAMETERS FOR SIMULATION

\begin{tabular}{|l|l|}
\hline Filter circuit components & $\mathrm{L} 2=100 \mu \mathrm{H}, \mathrm{C} 1=5 \mu \mathrm{F}$ \\
\hline $\begin{array}{l}\text { Heating coil parameters (reflected } \\
\text { values) }\end{array}$ & $\mathrm{L} 1=160 \mu \mathrm{H}, \mathrm{R} 1=0.002 \Omega$ \\
\hline Charging capacitors (C2 \& C3) & $0.4 \mu \mathrm{F}$ \\
\hline Snubbed resistors (R2 \& R3) & $470 \Omega$ \\
\hline Switching frequency & $33 \mathrm{kHz}$ \\
\hline
\end{tabular}

Firstly, the inverter circuit is simulated with IGBT as power switch. There after switching frequency is changed by in step of 3 to $5 \mathrm{kHz}$. In each case, the coil current waveform across it have been recorded $\&$ investigated.

\section{RESULTS AND DISCUSSIONS}

With the chosen different switching frequency, following current waveforms through induction coil are obtained using P-SIM software:

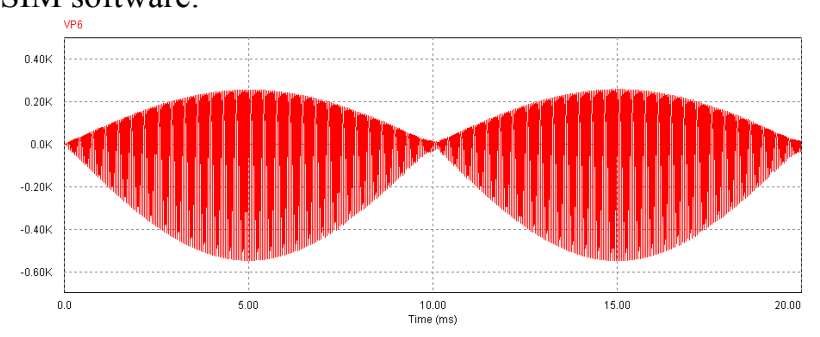

Fig. 4. Wave-form for $20 \mathrm{kHz}$ switching frequency.

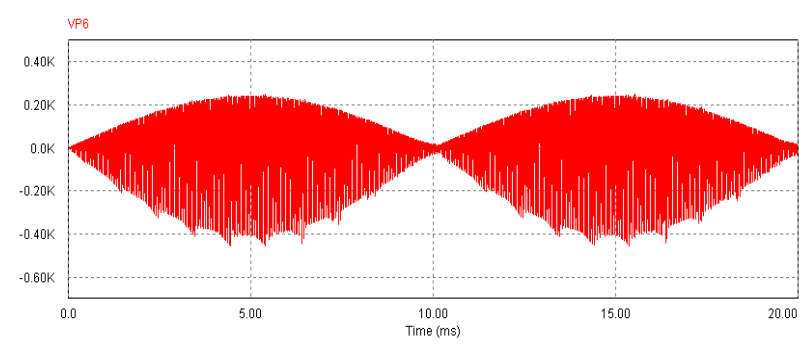

Fig. 5. Wave-form for $23 \mathrm{kHz}$. switching frequency.

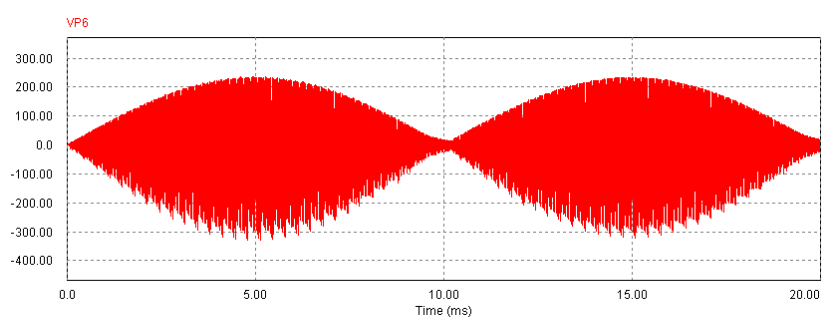

Fig. 6. Wave-form for $27 \mathrm{kHz}$. switching frequency. 


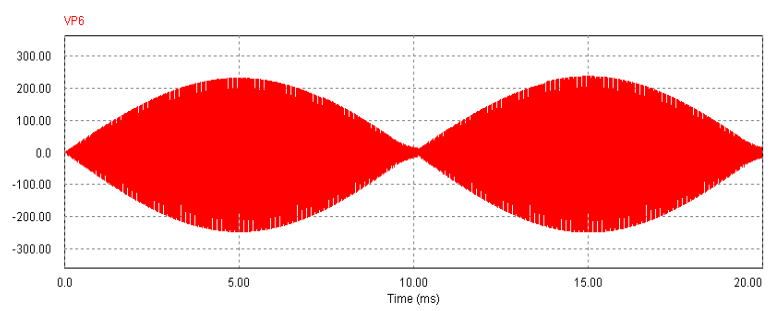

Fig. 7. Wave-form for $30 \mathrm{kHz}$. switching frequency.

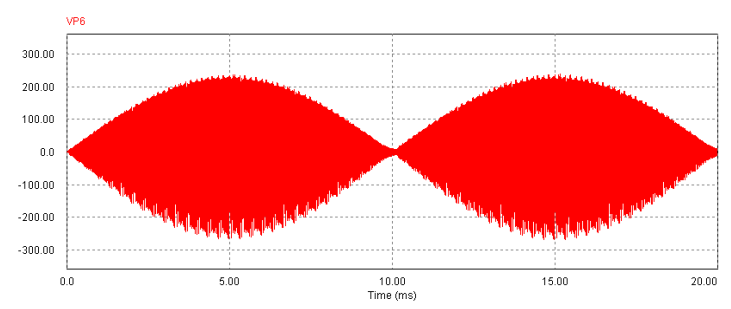

Fig. 8. Wave-form for $33 \mathrm{kHz}$. switching frequency.

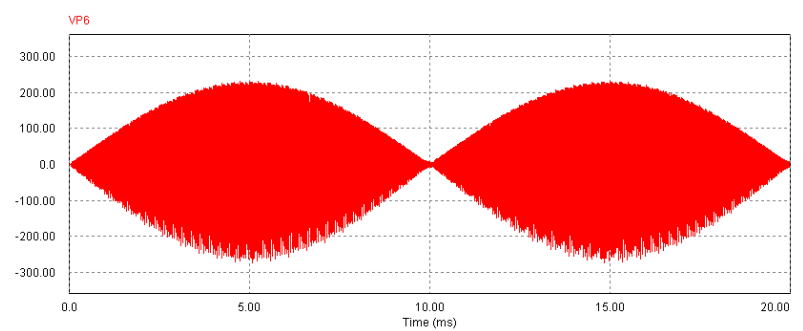

Fig. 9. Wave-form for $38 \mathrm{kHz}$. switching frequency.

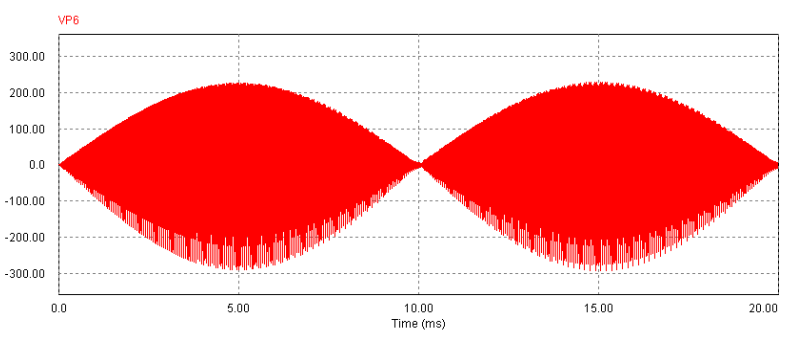

Fig. 10. Wave-form for $40 \mathrm{kHz}$. switching frequency.

The wave forms shown above, it is seen that the magnitude of the current wave is not same for the upper quardent and lower quardent for different switching frequency, but when the resonance has occurred then the voltage wave shapes are equal in magnitude for both the upper and lower quardent. At resonance high amount of eddy current is produced which will flow through the heating coil and produce desired large amount of heat.

Using IGBT in the mirror inverter circuit, it is observed in Figure 8 that at $33 \mathrm{kHz}$ switching frequency magnitude of current through the coil has almost equal in both positive and negative halves. Such a peak to peak symmetrical current produces more heat. Hence heating effect becomes very prominent for the same operating frequency range.

From Fig. 4 to Figure 10 except Fig. 8, it is clear that in the mirror inverter circuit, coil current doesn't have equal positive and negative peaks. Hence, rms value of the current will be less. So heating effect will also be less compared to the current at frequency of $33 \mathrm{kHz}$ which is also verified from system efficiency calculation of induction heater obtained through real-time experimental set-up.

Using water as fluid, the sample efficiency calculation of induction heating-range for single layer secondary metallic object at set-II temperature setting is given below :

Input no load current $=\mathrm{I}_{\mathrm{O}}=0.06 \mathrm{amp}$

Input load current $=\mathrm{I}_{\mathrm{L}}=1.53 \mathrm{amp}$

Input voltage $=\mathrm{V}_{\mathrm{I}}=220.4$ volt

Initial temperature of fluid (Ambient) $\mathrm{T}_{1}=21^{\mathrm{O}} \mathrm{C}$

Final temperature of fluid $\mathrm{T}_{2}=92.75^{\circ} \mathrm{C}$

Initial fluid mass (water), $\mathrm{m}_{\mathrm{I}}=0.1675 \mathrm{~kg}$

Stainless steel package weight, $\mathrm{ms}=0.07314 \mathrm{~kg}$

Final mass of fluid after experiment, $\mathrm{mf}=0.1395 \mathrm{~kg}$

Mass of evaporated fluid $=\mathrm{m}_{\mathrm{ev}}=\mathrm{m}_{\mathrm{i}}-\mathrm{m}_{\mathrm{f}}=0.1675-0.1395=$ $0.028 \mathrm{~kg}$.

Total time taken to reach final temperature $=360 \mathrm{sec}$

Taking $\mathrm{L}=2256.9 \mathrm{~kJ} / \mathrm{kg}$ (some fluid will be evaporated which is nearer layer of steel vessel)

Heat power transferred to fluid, $\mathrm{P}_{\mathrm{o}}=\left\{\mathrm{m}_{\mathrm{I}} \mathrm{C}_{\mathrm{p}}\left(\mathrm{T}_{2}-\mathrm{T}_{1}\right)+\mathrm{m}_{\mathrm{ev}} \mathrm{L}\right\} /$ time in $\mathrm{sec}=113504.4 / 360 \mathrm{~J} / \mathrm{sec}=315.29 \mathrm{~W}$

Input power taken from source, $\mathrm{P}_{\mathrm{I}}=\mathrm{V}_{\mathrm{I}} \mathrm{I}_{\mathrm{L}} \operatorname{Cos} \phi$ (here $\operatorname{Cos} \phi=1$ ) $=220.4 \times 1.53=337.212 \mathrm{~W}$

Efficiency of the heating system at temperature Set-II $=\eta_{\mathrm{h} 2}=$ $315.29 / 337.212=0.935=93.5 \%$.

The system efficiency calculation of induction heater obtained through real-time experimental set-up is shown in Table II.

TABLE. II: SYSTEM EFFICIENCY AT DIFFERENT OPERATING FREQUENCY OF INDUCTION HEATER

\begin{tabular}{|c|c|}
\hline $\begin{array}{c}\text { Operating frequency of } \\
\text { induction heater }(\mathrm{kHz})\end{array}$ & $\begin{array}{c}\text { System efficiency of induction } \\
\text { heater }(\%)\end{array}$ \\
\hline 20 & 72.1 \\
\hline 23 & 78.9 \\
\hline 27 & 82.8 \\
\hline 30 & 84.7 \\
\hline 33 & 93.5 \\
\hline 38 & 79.8 \\
\hline 40 & 69.5 \\
\hline
\end{tabular}

From the results of Table II, it has been observed that $33 \mathrm{kHz}$ switching frequency is most suitable for H. F. mirror inverter which is shown in P-SIM simulation as well as verified from real-time experiment.

\section{CONCLUSIONS}

After having compared the simulation results, it is quite obvious that using IGBT as a power semiconductor switch in H.F. mirror inverter is advantageous for induction heating purposes for frequency below $50 \mathrm{kHz} \&$ particularly at $33 \mathrm{kHz}$, the effect is highly sound. At $33 \mathrm{kHz}$ switching frequency magnitude of the current through the heating coil has almost same in either direction. Hence, this switching frequency is most suitable for H. F. mirror inverter employed in industrial induction heating.

\section{ACKNOWLEDGMENT}

Authors are thankful to the UNIVERSITY GRANTS COMMISSION, Bahadurshah Zafar Marg, New Delhi, India for granting financial support under Major Research Project on Simulation of high-frequency mirror inverter for energy efficient induction heated cooking oven w.e.f. $01 / 04$ / 2008 to $31 / 03 / 2011$. 


\section{REFERENCES}

[1] P. K. Sadhu, N. Jana, R. Chakrabarti, and D. K. Mittra "A Unique Induction Heated Cooking Appliances Range Using Hybrid Resonant Converter," - Int. J. of Circuits, Systems and Computers, World Scientific, Vol.14, Number 3, pp. 619-630, June, 2005

[2] P. K. Sadhu, N. Pal, R. N. Chakrabarti, and T.K Chatterjee, "Performance analysis of HF mirror inverter for energy efficient induction cooker appliance range," Int. Conf. on Modelling and simulation MS'07, University of Calcutta, December, 2007, pp. 444-448. 2007.

[3] A. Okuno, H. Kawano, J. Sun, M. Kurokawa, A. Kojina, and M. Nakaoka.: "Feasible development of soft-switched SIT inverter with load-adaptive frequency-tracking control scheme for induction heating," IEEE Trans. Ind Appl, 34, (4), pp. 713-718, 1998.

[4] P. K. Sadhu, N. Pal, D. Sinha, and A. Bandyopadhyay, "Energy Efficient Induction Heated Cooking - Range using MCT baesd Hybrid Resonant Converter", IEEE Proc. of the $2^{\text {nd }}$ Int. Conf. on Computer and Automation Engineering (ICCAE 2010) Vol. 5, February, 2010, pp. 637-641.2010.

[5] F. P. Dawson and P. Jain.: 'A comparison of load commutated inverter systems for induction heating and melting applications', IEEE Trans. Power Electron, 6, (3), pp. 430-441, and 1991.

[6] M. Nakaoka, "A Phase-difference angle control- mode PWM high-frequency resonant inverters using static induction-transistors and thyristors," in Proc. IEEE-PESC 87, June, 1987, pp. 674-681.1987.

[7] P. K. Sadhu, R. N. Chakrabarti, and S. P. Chowdhury, "An improved inverter circuit arrangement," Indian Patent No. 244527, December 9, 2010.

[8] S. A. Gonzalez, M. 1. Valla, and C. H. Muravchik, "Analysis and Design of Clamped-Mode Resonant Converters with Variable Load," IEEE Transactions on Industrial Electronics, vol.48, No. 4, pp. 812-819, August, 2001.

[9] P. K. Sadhu, S. K. Mukherjee, R. N. Chakrabarti, S. P. Chowdhury, and B. M. Karan, "Microprocessor-based energy efficient sterilization for surgical instrument using a new generation inverter topology," J. Energy, Heat and Mass Transfer, Vol. 23, No 1, pp. 39-53, March, 2001.

[10] H. W. Koertzen, J. D. Van Wyk, and J. A.Ferreira, 'Design of the half bridge series resonant converter for induction cooking, " IEEE Power Electronics Specialists Conf. (PESC) Rec, 1995, pp. 729-735.1995.

[11] S. Llorente, F. Monterde, J. M.Burdio, and J. Acero, "A comparative study of resonant inverter topologies used in induction cooker," IEEE Applied Power Electronics Conf. (APEC) Rec, 2002, .pp. 1168-1174.2002

[12] P. K. Sadhu, S. K. Mukherjee, R. N. Chakrabarti, S. P. Chowdhury, and B. M. Karan, "A new generation microprocessor based series resonant inverter for induction heating appliances," J. Industrial Engineering, Vol XXX, No. 9, pp. 10 -15, September, 2001.

[13] P. K. Sadhu, S. K. Mukherjee, R. N. Chakrabarti, S. P. Chowdhury, and B. M. Karan, "High efficient contamination free clean heat production," Indian Journal of Engineering \& Materials Sciences, National Institute of Science Communication, New Delhi, Vol-9, pp. 172-176, June, 2002.

[14] P. K. Sadhu, N. Pal, A. Bandyopadhyay, and D. Sinha, "Review of Induction Cooking - a Health Hazards Free Tool to Improve Energy Efficiency as Compared to Microwave Oven," IEEE Proc. of The $2^{\text {nd }}$ Int. Conf. on Computer and Automation Engineering (ICCAE 2010), Volume 5, February, 2010, pp. 650-654. 2010.

[15] P. K. Sadhu, R. N. Chakrabarti, and S. P. Chowdhury, "A new generation fluid heating in non-metallic pipe-line using BJT and
IGBT," J. Institution of Engineers (I), Vol. 82., pp. 273-280., March , 2002.

[16] P. K. Sadhu, R. N. Chakrabarti, and S. P. Chowdhury, "A cooking apparatus using high frequency induction heating," Indian Patent No. 216361, March 12, 2008.

[17] P. K. Sadhu, N. Pal, R. Chakrabarti, and D. K. Mittra, "A dynamic model for the simulation of induction cooktop," J. Industrial Engineering, Vol XXXV, No 6, pp. 37-41, June, 2006.

[18] M. K. Kazimierczuk, "Class D voltage-switching MOSFET power amplifier," IEE Proceedings-B, No. 6, November, 1991, pp. 285-296.1991.

[19] .S. Wang, K. Izaki, I. Hirota, H. Yamashita, H. Omori, and M. Nakaoka. "Induction-heated cooking appliance using new quasi-resonant ZVS-PWM inverter with power factor correction," IEEE Truns. Ind Appl, 34, (4), pp. 705-712, 1998.

[20] P. K. Sadhu, S. K. Mukherjee, R. N. Chakrabarti, S. P. Chowdhury, and B. M. Karan, "A new generation microprocessor based radio-frequency operated induction heating for sterilization and boiler plant," J. IEEMA, Vol XXII, No 2, , pp. 36-48, February, 2002.

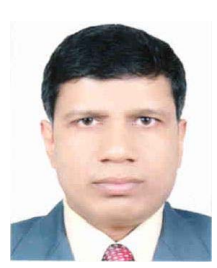

Nitai Pal received his B.Tech. and M.Tech. degrees in Electrical Engineering from University of Calcutta, West Bengal, India. He received his Ph.D. (Engineering) from Jadavpur University, West Bengal, India. He has total experience of twelve years in teaching. He is currently working as an Assistant Professor in the Department of Electrical Engineering, Indian School of Mines, Dhanbad, Jharkhand, India. He has several publications in Journals, International \& National conferences. He is the co-investigator of Govt funded project. His current areas of interest are Power electronics application, application of high frequency converters, energy efficient devices, energy efficient drives, lighting and communication systems for underground coal mines etc.

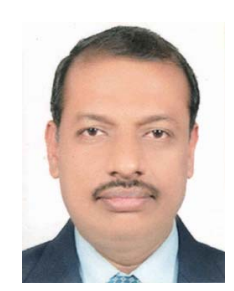

Pradip Kumar Sadhu received his Bachelor, Post-Graduate and Ph.D.(Engineering) degrees in 1997, 1999 and 2002 respectively in Electrical Engg. from Jadavpur University, West Bengal, India. Currently, he is working as a Professor in Electrical Engineering Department of Indian School of Mines, Dhanbad, India. He has total experience of 18 years in teaching and industry. He has four Patents. He has several journal and conference publications in national and international level. He is principal investigator of few Govt. funded projects. He has guided a large no. of doctoral candidates and M.Tech students. His current areas of interest are power electronics applications, application of high frequency converter, energy efficient devices, energy efficient drives, computer aided power system analysis, condition monitoring, lighting and communication systems for underground coal mines.

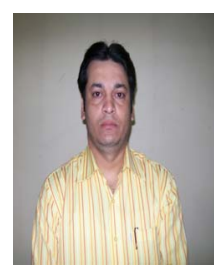

Atanu Bandyopadhyay completed B.E. from Nagpur University, India. He received his M.E. degree from Bengal Engineering and Science University, Shibpur, West Bengal, India. He has total experience of eleven years in teaching and industry. He is currently working as an Assistant Professor in the Department of Electrical Engineering, Asansol Engineering College, Asansol-05, West Bengal, India $\mathrm{He}$ is presently prusuing Ph.D. Programme under external registration at the Department of Electrical Engineering, Indian School of Mines, Dhanbad - 826004, India. His research interests include induction heating and high frequency switching in power electronics. 